\title{
Follow-Up Comparisons of Intervention and Comparison Schools in a State Tobacco Prevention and Control Initiative
}

\author{
Phyllis Gingiss, Melynda Boerm, Cynthia Roberts-Gray
}

\begin{abstract}
This study provides information about prevention and control practices in intervention and comparison secondary schools 2 years after the start-up of the Texas Tobacco Prevention Initiative. The intervention, which was funded through the Texas Department of State Health Services, consisted of guidance, training, technical assistance, and reimbursement of approximately $\$ 2000$ per year for program expenses. Self-administered written surveys for Principals and Health Coordinators, based on the School Health Education Profile Tobacco Module, were designed for periodic assessment of the status of school programs. Surveys were sent in 2002 to intervention $(n=74)$ and comparison $(n=60)$ schools. Response to the Principal Survey was received from $109(81 \%)$ schools, and response to the Health Coordinator Survey was received from $84(63 \%)$ schools. Survey analysis showed that intervention schools more frequently $(p \leq .05)$ reported: (1) being extremely or moderately active in student cessation support, teacher training, policy development, family involvement, and assessment of the prevention program; (2) using recommended curricula, offering more tobacco-related lessons, involving more teachers, and using more recommended teaching methods such as role-playing, simulations or practice, and peer educators; and (3) having more interest in staff development and more funding to purchase release time. Similarities across schools are provided, as well as recommendations for future planning. (J Sch Health. 2006;76(3):98-103)
\end{abstract}

$\mathbf{S}_{\mathrm{cith}}^{\mathrm{ch}}$ chool-based programs are widely recognized as a crucial component of comprehensive strategies for preventing tobacco use and addiction. ${ }^{1}$ Schools are better positioned to help develop and reinforce the norms that govern adolescent and adult behavior than any institution except the family. School health programs play an important role in reducing adolescent tobacco use. When properly implemented, school programs can lower smoking prevalence by $25 \%$ to $60 \% .^{2}$ Studies in Texas showed similar results for school-based programs combined with a media campaign. The average rate of tobacco use was $40 \%$ lower for program students than for those at comparison schools. ${ }^{3}$

Effective tobacco control programs have been developed and tested. ${ }^{4}$ However, as noted in the Surgeon General's Report, ${ }^{4}$ little evidence exists that programs to prevent tobacco use that have been shown to be effective in controlled studies can be adapted effectively to statewide use. Often, school-based programs that were effective in controlled research studies have difficulties transferring to naturalistic settings. ${ }^{5-8}$

When the state of Texas won a lawsuit against the tobacco industry, Texas Department of State Health Services (TDSHS) received a legislative mandate to implement and evaluate a variety of single- and multiple-activity options in tobacco prevention and control in a geographically defined area of East Texas. A key component was establishment and operation of school-based interventions. ${ }^{9}$

In the spring 2000, prior to initiation of funding or training, technical assistance, and program implementation, ${ }^{10}$ we conducted a baseline study that showed no significant initial differences between schools assigned to the intervention and those assigned to the comparison group. ${ }^{10}$ This follow-up study was designed to provide information 2 years

Phyllis Gingiss, DrPH, Professor of Public Health Education, and Director of Health Network for Evaluation and Training Systems, (pmgingiss@ uh.edu), Department of Health and Human Performance, University of Houston, 3855 Holman, 104 Garrison Gym, Houston, TX 77204-6015; Melynda Boerm, MEd, Program Manager, (mboerm@uh.edu), Health Network for Evaluation and Training Systems, University of Houston, 3855 Holman, 104 Garrison Gym, Houston, TX 77204-6015; and Cynthia Roberts-Gray, PhD, Program Evaluation Specialist, (cindyrobertsh@ aol.com), Resource Network, 3002 Avenue O 1/2, Galveston, TX 77550. later about (1) the characteristics of school tobacco prevention and control policies and practices in the East Texas service area and (2) a comparison of tobacco-related practices in intervention and comparison schools.

\section{Intervention Description}

\section{METHODS}

The Texas Tobacco Prevention Initiative placed a Tobacco Specialist at each of 4 Regional Education Service Centers (ESC) serving the East Texas study area. Their responsibilities included coordination, distribution and management of funding, training, and technical assistance for intervention schools in respective service areas. Contractual agreements were issued to intervention schools to (a) participate in training organized by their ESC on tobacco issues and curricula and (b) conduct tobacco-use prevention education (TUPE) with the designated curriculums of Project TNT (Towards No Tobacco) at the middle school level and NOT (Not On Tobacco) at the high school level. Additional contractual requirements were to (a) conduct at least 1 tobacco prevention event; (b) provide education and training for parents and staff regarding local policies and ordinances as well as state tobacco laws; (c) establish STARS, PALS, or Teens Against Tobacco Use (TATU) groups or other peer mentor programs at the high school level; and (d) participate in evaluation and surveillance activities. School contracts and training encouraged planning and implementing the above activities based on the Guidelines for school health programs to prevent tobacco use and addiction. ${ }^{11}$ Each school received an allocation of approximately $\$ 2000$ per year to be used for materials, supplies and small equipment, in-service release time, training, and travel to tobaccorelated meetings.

\section{Participants}

The baseline sample of schools was randomly selected by TDSHS in SY2000 from schools serving students in grades 6 through 12 in the East Texas study area. A representative sample of schools was selected. Participating schools were located in 69 districts in a 7-county study area. The original SY2000 sample of 171 schools was 
drawn with probability proportional to study-area size and school condition (intervention or comparison). Among these schools, 134 participated in the baseline study. This sample was retained and used in this SY2002 follow-up.

\section{Instruments}

Principal and Health Coordinator Surveys were designed to correspond to the 2000 School Health Education Profile Tobacco Module (SHEP-TM) developed by the Centers for Disease Control and Prevention ${ }^{12}$ and to probe use of "best practice guidelines" identified in the Guidelines for school health programs to prevent tobacco use and addiction. ${ }^{11}$ The self-administered survey tools were modified and adapted for Texas based on input from 13 of the 20 regional health coordinators.

The Principal Survey asked how active the school was during the preceding school year in implementing each of the 8 health program components identified in the Guidelines $^{11}$ and requested descriptive information regarding policy development, locations where policy prohibiting tobacco use is enforced (eg, in school buses and other vehicles), actions taken when individuals are caught using tobacco, and sources of support for smoking cessation for students, faculty, and staff.

The Health Coordinator Survey asked if prevention information is provided to students in classroom instruction, the number of lessons taught, the number of teachers involved, the classes in which the instruction is taught, curricula used, methods of instruction, topics and skill areas covered, and ways families are involved. The Health Coordinator Survey also asked about interest in offering instruction, preferences for tobacco-related staff development, and teachers' beliefs about whether classroom instruction in tobacco prevention will influence students' behaviors. Copies of the surveys are available. ${ }^{13}$

\section{Procedures}

In the spring of 2002, names of principals and health coordinators were updated and surveys mailed to the schools. A second set of surveys was mailed a month later to nonresponding schools, followed by phone reminders.

\section{Data Analysis}

Frequencies, means, and chi-square analysis were used to report the status of school TUPE and to compare differences in school tobacco prevention and control activities in intervention and comparison schools at follow-up. A significance level of $\leq .05$ was established for all analyses.

\section{RESULTS}

Responses to the Principal Survey were received from $109(81 \%)$ and responses to the Health Coordinator Survey were received from $84(63 \%)$ of the 134 schools in SY2002. Schools participating in the Principal Survey included 43 intervention schools and 66 comparison schools. Among participants in the Health Coordinator Survey, 36 represented intervention schools and 48 represented comparison schools.

\section{Principal Survey Results}

Level of Activity of Tobacco Program Components. Almost all the schools $(92 \%)$ were reported to be extremely/moderately active in the enforcement of the school policy on tobacco use, and $75 \%$ were extremely/ moderately active in TUPE. However, less than half of all schools were extremely/moderately active in the assessment of prevention programs $(48 \%)$, student cessation support (47\%), teacher training (37\%), and establishment or modification of school tobacco policies (35\%). Less than one third of schools were extremely/moderately active in faculty and staff cessation $(30 \%)$ or family involvement in student tobacco programs $(21 \%)$.

Figure 1 presents differences between intervention and comparison schools. Significantly more intervention than comparison schools were extremely/moderately active in the assessment of prevention programs $\left(\chi_{3}^{2}=\right.$ $11.5, \mathrm{p}=.009)$, student cessation support $\left(\chi_{3}^{2}=7.9\right.$, $\mathrm{p}=.047)$, teacher training for TUPE $\left(\chi_{3}^{2}=8.1, \mathrm{p}=.04\right)$, establishment or modification of school tobacco policies $\left(\chi_{3}^{2}=7.9, \mathrm{p}=.048\right)$, and family involvement $\left(\chi_{3}^{2}=11.5\right.$, $\mathrm{p}=.009)$.

Development of School Policy. Less than half of schools $(39 \%)$ reported parent involvement in school tobacco policy development and use. However, intervention schools had significantly more parental involvement $(56 \%)$ than comparison schools $(27 \%)\left(\chi_{1}^{2}=9.3, \mathrm{p}=.01\right)$.

Almost all the school principals $(95 \%)$ reported being extremely/moderately familiar with Texas Senate Bill 1, ${ }^{14}$ which requires schools to prohibit tobacco use and student possession of tobacco products, as well as enforcement of tobacco policies.

Enforcement of Tobacco Policies. Policies prohibiting tobacco use in school buildings, on school grounds, and in school vehicles were always/almost always enforced by $95 \%$ of schools, as were policies pertaining to off-campus school-sponsored events $(93 \%)$. When students were caught using tobacco, the following actions were reported to be taken always/almost always: (a) referral to the school administrator $(96 \%)$, (b) parents or guardians were informed (96\%), (c) in-school suspension $(82 \%)$, (d) referral to legal authorities (49\%), (e) referral to the school counselor $(17 \%)$, and (f) encouragement of participation in an assistance program (12\%).

When faculty and staff were caught using tobacco, the following actions were taken always/almost always:(a) provision of oral or written reprimand $(68 \%)$, (b) referral to a school or district administrator (67\%), and (c) encouragement to participate in an assistance program (12\%).

Provision of Tobacco Cessation Support. Tobacco cessation support was provided for students by $26 \%$ of schools and for faculty and staff by $5 \%$ of schools. Student referrals to off-site tobacco cessation programs were provided in $43 \%$ of schools and to faculty and staff in $31 \%$ of schools. Results of policy enforcement and tobacco cessation support were similar among intervention and comparison schools.

\section{Health Coordinator Survey Results}

Classroom Instruction on Tobacco Prevention. In most schools (93\%), student information on tobacco prevention 
Percentage of Intervention and Comparison Schools Extremely or Moderately Active in Centers for Disease Control and Prevention School Guidelines Components at Follow-Up (2002)

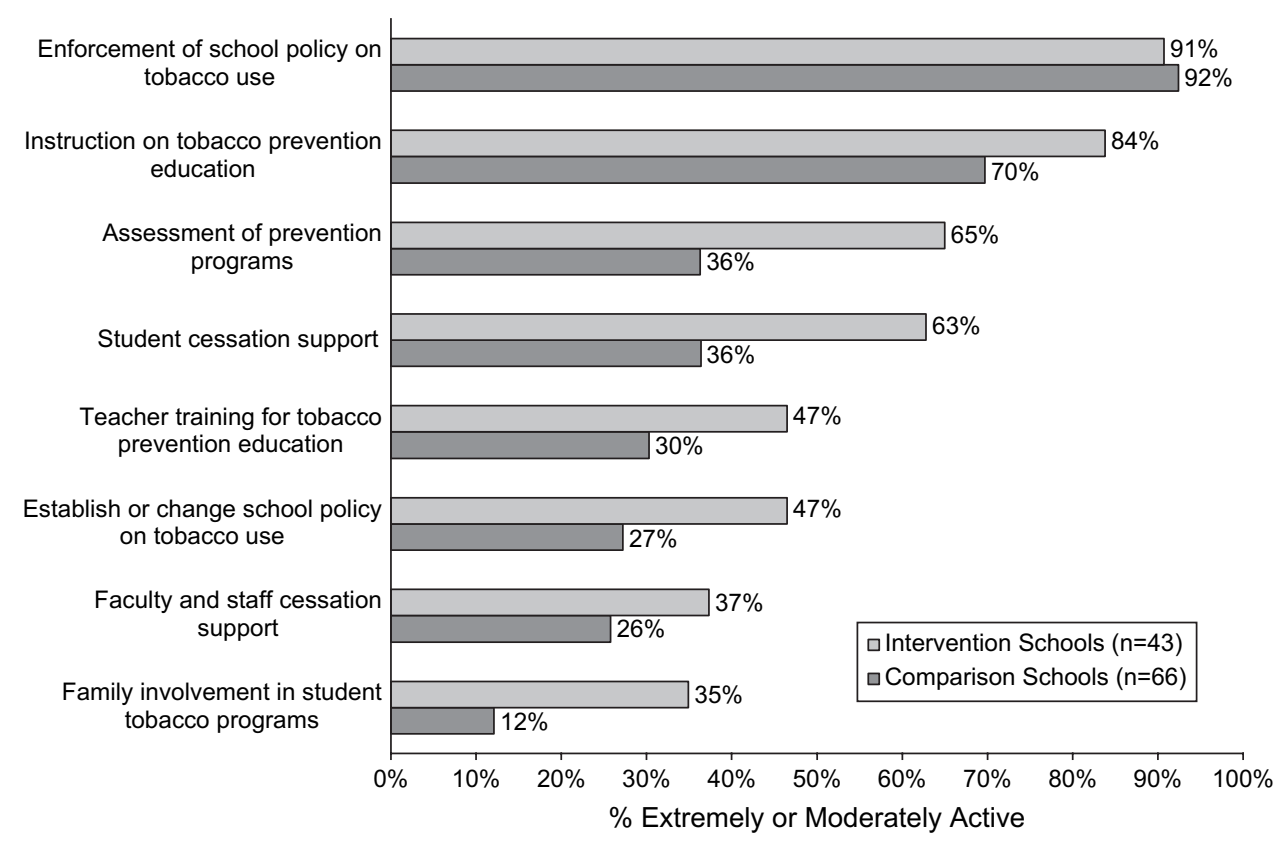

was provided through classroom instruction. Health Coordinators stating that TUPE was not provided at their school through classroom instruction were instructed to skip survey questions describing those activities. Results presented for the remainder of this section are from the 78 schools providing TUPE classroom instruction.

Among schools providing TUPE through classroom instruction $(\mathrm{n}=78), 39 \%$ offered TUPE in 6 th grade, $41 \%$ in 7 th grade, $36 \%$ in 8 th grade, $39 \%$ in 9th grade, $36 \%$ in 10 th grade, $33 \%$ in 11 th grade, and $33 \%$ in 12 th grade.

Approximately one third of the 78 schools provided 5 or more TUPE classroom lessons (Table 1). Two thirds $(n=52)$ of the 78 schools had 3 or more teachers spending 1 or more classes per year on TUPE. Among these 52 schools, 18 involved 5 or more teachers. Significantly, more intervention than comparison schools provided 10 or more classroom lessons on TUPE $\left(\chi_{4}^{2}=11.9, \mathrm{p}=.02\right)$.

Most schools $(80 \%)$ included units, lessons, or activities on TUPE in health class. Lessons also were presented in the following classes: physical education (44\%), science $(42 \%)$, family life education or life skills $(26 \%)$, and home economics $(23 \%)$. One fourth of schools $(27 \%)$ provided TUPE in "another" class.

As presented in Table 2, overall, few schools (22\%) offered the state-recommended curriculum, Project TNT at the middle school level or NOT for high schools. Eighteen percent reported using TATU. Less than 20\%, respectively, used Life Skills Training, Get Real About Tobacco, Project Alert, or Rebels. Forty-nine percent of schools reported using another curriculum for TUPE.

Intervention schools were significantly more likely to use recommended curricula: Project TNT $\left(\chi_{1}^{2}=16.1\right.$, $\mathrm{p}=.001)$, TATU $\left(\chi_{1}^{2}=11.1, \mathrm{p}=.001\right)$, and $\operatorname{NOT}\left(\chi_{1}^{2}=7.7\right.$, $\mathrm{p}=.01)$. More comparison schools reported using "other" curriculums $\left(\chi_{1}^{2}=12.3, \mathrm{p}=.001\right)$.

Among schools providing TUPE through classroom instruction (Table 3), traditional instructional methods such as lectures, group discussions, films or videos, and seatwork were used most frequently as the primary means of instruction. Student-centered, experiential, interactive methods such as role-playing, simulations or practice, special projects, peer educators, and the Internet were used by

\begin{tabular}{|c|c|c|c|}
\hline \multicolumn{4}{|c|}{$\begin{array}{c}\text { Table } 1 \\
\text { Number of Lessons Dedicated to Tobacco Use } \\
\text { Prevention Education Through } \\
\text { Classroom Instruction* }\end{array}$} \\
\hline $\begin{array}{l}\text { Number of } \\
\text { Lessons }\end{array}$ & $\begin{array}{l}\text { Overall } \\
(\mathrm{n}=78) \\
(\%)\end{array}$ & $\begin{array}{l}\text { Intervention } \\
(\mathrm{n}=35) \\
(\%)\end{array}$ & $\begin{array}{c}\text { Comparison } \\
(\mathrm{n}=43) \\
(\%)\end{array}$ \\
\hline $\begin{array}{l}\text { Greater than } \\
10 \text { lessons }\end{array}$ & 8 & 17 & 0 \\
\hline 5-10 lessons & 23 & 29 & 19 \\
\hline 2-4 lessons & 33 & 23 & 42 \\
\hline Single lesson & 18 & 20 & 16 \\
\hline $\begin{array}{c}\text { Infused into } 1 \text { or } \\
\text { more lessons }\end{array}$ & 18 & 11 & 23 \\
\hline
\end{tabular}


less than half of schools. Intervention schools more frequently included recommended approaches such as roleplaying, simulations or practice $\left(\chi_{1}^{2}=12.3, \mathrm{p}=.001\right)$, and peer educators $\left(\chi_{1}^{2}=7.4, \mathrm{p}=.01\right)$.

Family Involvement in Tobacco Prevention. Health coordinators at most schools indicated that their school did not have active family involvement across multiple TUPE components. Less than one third of all schools reported high/moderate levels of family involvement in each of the following areas: tobacco policy (30\%), organizations such as the Parent Teacher Association/Parent Teacher Organization (PTA/PTO) (18\%), school and community activities (16\%), student tobacco cessation (13\%), program planning or implementation $(12 \%)$, or classroom instruction $(11 \%)$. Intervention schools had significantly higher involvement in student tobacco cessation compared to comparison schools $\left(\chi_{3}^{2}=8.1, \mathrm{p}=.05\right)$. Of note, $58 \%$ of intervention schools and $65 \%$ of comparison schools reported no family involvement with student tobacco cessation.

Staff Development for Tobacco Prevention. Across all schools, more than one half $(58 \%)$ did not report a major increase in staff development. Funding was reported to be available to purchase release time to attend staff development in only $32 \%$ of schools. Three of every 4 schools (73\%) expressed some interest in staff development, although the level of interest was predominantly low.

Intervention schools more frequently reported an increase in staff development for TUPE since $2000\left(\chi_{3}^{2}=12.5\right.$, $\mathrm{p}=.01)$, more funding availability to purchase release time for staff development $\left(\chi_{2}^{2}=7.9, \mathrm{p}=.02\right)$, and greater interest in additional staff development $\left(\chi_{3}^{2}=11.1, \mathrm{p}=.01\right)$.

Provision of Tobacco Cessation Services. Information on tobacco cessation was provided for students through school sources in $62 \%$ of all schools and through community sources in $35 \%$ of all schools. Intervention schools were more likely to use school $\left(\chi_{1}^{2}=7.5, \mathrm{p}=.01\right)$ and community $\left(\chi_{1}^{2}=6.7, \mathrm{p}=.01\right)$ sources to provide cessation

\begin{tabular}{|c|c|c|c|}
\hline \multicolumn{4}{|c|}{$\begin{array}{c}\text { Table } 2 \\
\text { Classroom Curricula Used for Tobacco Use } \\
\text { Prevention Education }\end{array}$} \\
\hline Curriculum & $\begin{array}{l}\text { Overall } \\
(n=78) \\
(\%)\end{array}$ & $\begin{array}{l}\text { Intervention } \\
(\mathrm{n}=35) \\
(\%)\end{array}$ & $\begin{array}{c}\text { Comparison } \\
(\mathrm{n}=43) \\
(\%)\end{array}$ \\
\hline $\begin{array}{l}\text { Toward No } \\
\text { Tobacco* }\end{array}$ & 22 & 43 & 5 \\
\hline $\begin{array}{l}\text { Teens Against } \\
\text { Tobacco Use }\end{array}$ & 18 & 34 & 5 \\
\hline Life Skills Training & 17 & 11 & 21 \\
\hline $\begin{array}{l}\text { Get Real } \\
\text { About Tobacco }\end{array}$ & 12 & 17 & 7 \\
\hline Project Alert & 12 & 17 & 7 \\
\hline Not On Tobacco* & 8 & 17 & 0 \\
\hline Rebels & 1 & 3 & 0 \\
\hline Other* & 49 & 29 & 65 \\
\hline
\end{tabular}

information for students. Information on tobacco cessation was provided for faculty and staff through school sources in $33 \%$ of schools and through community sources in $23 \%$ of schools. No differences across conditions were noted.

\section{DISCUSSION}

A number of common strengths and concerns were identified among all schools. In addition, a notable number of areas were identified in which programs at intervention schools were stronger than those at comparison schools at 2-year follow-up.

Common Strengths. Almost all principals who participated in the current study reported familiarity and compliance with the state law prohibiting use of tobacco at schools. Most schools were reported to take positive actions when students, faculty, or staff were caught violating school tobacco policies. Texas Senate Bill 1 may have facilitated the high rate of school enforcement practices. ${ }^{14}$ School policy-related practices reported in this study are considerably higher than those reported in Profiles $2002^{15}$ or School Health and Policies and Programs Study $2000 .{ }^{16}$ As in the research of Blake et $\mathrm{al}^{17}$ regarding influential, state-level HIV policies, the presence of a strong state law enhanced the scope and enforcement levels of our schools' tobacco policies. However, even in the circumstances just noted, constant reinforcement of school administrators, teachers, and staff from the state, regional, and district levels is essential to maintain awareness and commitment to policy enforcement over time. ${ }^{18}$ These needs become magnified as new personnel rotate through schools. For example, when we called to verify names/positions at the schools for this follow-up study, we discovered that $40 \%$ (44/109) of the original principals in our sample had been replaced during the past 2 years. This turnover could pose a threat to sustained implementation of both enforcement

\section{Table 3 \\ Methods Used for Provision of Tobacco Use Prevention Education}

\begin{tabular}{|c|c|c|c|}
\hline Methods & $\begin{array}{c}\text { Overall } \\
(n=78) \\
(\%)\end{array}$ & $\begin{array}{l}\text { Intervention } \\
(\mathrm{n}=35) \\
(\%)\end{array}$ & $\begin{array}{c}\text { Comparison } \\
\text { (n=43) } \\
(\%)\end{array}$ \\
\hline Lectures* & 88 & 77 & 95 \\
\hline Group discussions** & 86 & 94 & 79 \\
\hline Films or videos & 78 & 80 & 77 \\
\hline Seatwork & 75 & 77 & 74 \\
\hline Adult guest speakers & 44 & 49 & 40 \\
\hline $\begin{array}{l}\text { Role-playing and } \\
\text { simulations or } \\
\text { practice }^{\star *}\end{array}$ & 42 & 63 & 26 \\
\hline Special projects & 35 & 43 & 28 \\
\hline Peer educators ${ }^{* *}$ & 31 & 46 & 19 \\
\hline The Internet & 22 & 26 & 19 \\
\hline
\end{tabular}


policies and instructional programs unless plans for sustainability are developed within each campus.

The scope and nature of TUPE provided in classroom instruction was another common strength. More than two thirds of intervention and comparison schools were reported to be at least moderately active in implementing instruction at follow-up.

Widespread Challenges. Common circumstances that need strengthening among all schools include (1) the use of more nonpunitive, remedial methods for students, faculty, and staff caught using tobacco; (2) increased provision of tobacco cessation services and information for students, faculty, and staff; (3) expansion of the number of lessons dedicated to TUPE; (4) active involvement of increased numbers of teachers and staff; (5) use of research-derived, published curricula which use interactive, student-centered methods such as role-playing, simulation or practice, and peer educators; and (6) greater integration of TUPE through other subjects. While greater strength was demonstrated among intervention schools in some of these areas, all schools had less than ideal levels of implementation.

Of particular concern, family involvement in tobacco policy development and enforcement was very low across more than two thirds of all surveyed schools. Similar to our results, Blake et $\mathrm{al}^{17}$ noted that development of parent and community educational programs was the least frequently adopted recommendation from national or state policy recommendations for "best practice" among AIDS/HIV prevention education policies. While expanded family involvement is widely recognized to be imperative for programs to maximize full student benefits from interventions and is included as a best practice guidelines, the underutilization of this component needs far more attention.

Differences between Intervention and Comparison Schools. At follow-up, intervention schools were more likely than comparison schools to be extremely/moderately active in student cessation support, teacher training, policy development, family involvement, and assessment of the prevention program. Intervention schools also were more often reported to be using recommended curricula, offering more tobacco-related lessons, involving more teachers, and using more recommended teaching methods such as role-playing, simulations or practice, and peer educators. More interest was reported in staff development at intervention schools.

The intervention school reports of many strengths relative to the comparison schools suggest several factors at work. First, the positive gains in classroom instruction implementation are consistent with the primary focus of training, which emphasized preparation of teachers for classroom instruction in TUPE. Second, the use of Tobacco Specialists at the Regional ESC as linking agents between the state and local schools may have facilitated intervention school progress. Linking agents have been shown to play an essential role in implementing public health programs. The linkage approach to the diffusion planning process consists of representatives of the resource system, the user system, change agents, and strategic planning activities. ${ }^{19-23}$ In this instance, the linking agents were responsible for school selection into the program, coordinating fiscal management of schools within their region, staff development and technical assistance, and facilitation of state-level evaluations. Linking agents further facilitate implementation by troubleshooting problems that arise and answering questions. ${ }^{24}$ State tobacco funds were used to support these positions and regional representatives participated in state-level planning meetings and communications. In Texas, the model used has been perceived to be an effective approach for managing diffusion of a program spread over geographically disparate and diverse settings.

The relatively more positive status of tobacco prevention and control at intervention schools was achieved despite the absence of a state-level health course requirement in Texas middle schools. At baseline, about half the districts had locally adopted a middle school health requirement. ${ }^{9}$ Our results in this study are consistent with our earlier report that districts adopting middle school health requirements were more frequently prone to provide in TUPE, teachers used more effective methods and were more receptive to further training, and schools provided more cessation support and counselor involvement. ${ }^{10}$ National data indicate that most states do have a health course requirement in middle school. ${ }^{15}$ When school interventions such as the ones reported are adopted and implemented in states with existing middle school health course requirements, measures of implementation among both intervention and comparison schools are anticipated to be higher than those currently reported.

\section{CONCLUSIONS AND RECOMMENDATIONS}

Approaches used by the TDSHS in its Texas Tobacco Prevention Initiative worked well in promoting recommended school practices to reduce tobacco use and addiction. Two years after start-up, practices at intervention schools were substantially stronger than those at comparison schools.

At both intervention and comparison schools, however, areas exist where additional development is needed. In particular, few schools have found ways to involve families in the development, implementation, and support of the school's tobacco policies and practices. Additionally, although intervention schools were more likely to be using recommended evidence-based curricula for prevention education, less than half of the schools were doing so, and even fewer were providing as many as 5 lessons for the students.

Although strategies used (low-level funding, multiple channel communications facilitated by a linking agent between state, region, and local schools, training, technical assistance, and support strategies) facilitated positive changes, consideration of how to further strengthen existing tobacco programs and maintain gains is needed. When examined several years after start-up, many of the Texas schools still had low implementation levels. ${ }^{25}$ The problem is not new. Research stresses the importance of infrastructure development to support and maintain new programs after implementation becomes routinized. ${ }^{21,24,26}$ The need exists for a broad-based approach, with attention to both users and administrators, to ensure new programs will be fully implemented and strengthened over time..$^{25-30}$

Our challenge is to diffuse successful program components within and across schools and increase sustainability. Only in this manner can successful tobacco programs reach our youth with sufficient strength to maximize opportunities to reduce tobacco use. 


\section{References}

1. Satcher D. School Health Education Profile Tobacco Module. Atlanta, Ga: Centers for Disease Control and Prevention; 2000.

2. National Cancer Policy Board, Institute of Medicine and National Research Council. State programs can reduce tobacco use. 2000. Available at: http://www.nap.edu/. Accessed April 25, 2005.

3. Meshack A, Hu S, Pallonen U, McAlister A, Gottlieb N, Huang P. Texas tobacco prevention pilot initiative: processes and effects. Health Educ Res. 2004;19(6):651-668.

4. US Department of Health and Human Services. Reducing Tobacco Use: A Report of the Surgeon General. Atlanta, Ga: Centers for Disease Control and Prevention, National Center for Chronic Disease Prevention and Health Promotion, Office on Smoking and Health; 2000.

5. Parcel GS, Ross JG, Lavin AT, Portnoy B, Nelson GD, Winters F. Enhancing implementation of the teenage health teaching modules. $J$ Sch Health. 1991;61(1):35-38.

6. Gottfredson D, Gottfredson G. Quality of school-based prevention programs: results from a national survey. J Res Crime and Delinq. 2002; 39:3-35

7. Elliott D, Mihalic S. Issues in disseminating and replicating effective prevention programs. Prev Sci. 2004;5:47-53.

8. Ennett S, Ringwalt C, Thorne J, et al. A comparison of current practice in school-based substance use prevention programs with meta-analysis findings. Prev Sci. 2003;4(1):1-14.

9. Texas Tobacco Prevention Initiative: Infrastructure and Baseline Data. Austin, Tex: Texas Dept of Health; 2001

10. Boerm MC, Gingiss PM, Huang P, Alo C, Kropp R. Baseline assessment of Tobacco Use Prevention Education (TUPE) in Texas secondary schools. In: Program and abstracts of the American School Health Association 75th Annual Conference; November 8, 2001; Albuquerque, NM.

11. Centers for Disease Control and Prevention. Guidelines for school health programs to prevent tobacco use and addiction. MMWR Morb Mortal Wkly Rep. 1994;43[RR-2].

12. Boerm MC, Gingiss PM, Roberts-Gray C. School Health Education Profile Tobacco Module (SHEP-TM): Adaptation and Use to Assess the Extent of Implementation of CDC Recommendations for "Best Practice" in School Tobacco Programs: Proceedings of the American School Health Association 76th National School Health Conference, Charlotte, NC. Houston, Tex: University of Houston; 2002.

13. Boerm M, Gingiss P. Status of school tobacco prevention and control two years after the beginning of the Texas Tobacco Prevention Initiative: comparisons of intervention and comparison schools. March, 2003 Available at: http://uh.edu/hnets/TobaccoSchEval.html. Accessed April 25, 2005.

14. Ratliff B. Senate Bill 1. 1. 5-30-1995. 74R 00433. \#38.006.00. Available at: http://www.capitol.state.tx.us/statutes/docs/ED/content/htm/ ed.002.00.000038.00.htm. Accessed May 16, 2005.
15. Whalen LG, Grunbaum JA, Kann L, Hawkins J, McManus T, Davis KS. School Health Profiles: Surveillance for Characteristics of Health Programs Among Secondary Schools (Profiles 2002). Atlanta, Ga: Centers for Disease Control and Prevention; 2004.

16. Small ML, Everett-Jones S, Barrios LC, et al. School policy and environment: results from the School Health and Policies and Programs Study 2000. J Sch Health. 2001;71(7):325-334.

17. Blake SM, Ledsky RA, Sawyer RJ, et al. Local school district adoption of state-recommended policies on HIV prevention education. Prev Med. 2005;440:239-248.

18. Tubman JG, Vento RS. Principal and teacher reports of strategies to enforce anti-tobacco policies in Florida middle and high schools. $J$ Sch Health. 2001;71(6):229-235.

19. Kolbe LJ, Iverson DC. Implementing comprehensive school health education: educational innovations and social change. Health Educ Q. $1981 ; 8: 57-80$

20. Orlandi MA, Landers C, Weston R, Haley N. Diffusion of health promotion innovations. In: Glanz K, Lewis FM, Rimer BK, eds. Health Behavior and Health Education: Theory, Research and Practice. San Francisco, Calif: Jossey-Bass; 1990:288-313.

21. Hord S, Hall G. Implementing Change: Patterns, Principles, and Potholds. Needham Heights, Mass: Allyn \& Bacon; 2000.

22. Gingiss PL, Gottlieb NH, Brink SG. Measuring cognitive characteristics associated with adoption and implementation of health innovations in schools. Am J Health Promot. 1994;8(3):294-301.

23. Roberts-Gray C, Solomon T, Gottlieb N, Kelsey E. Heart partners: a strategy for promoting effective diffusion of school health programs. $J$ Sch Health. 1998;68(3):106-110.

24. Oldenburg BF, Sallis JF, French ML, Owen N. Health promotion research and the diffusion and institutionalization of interventions. Health Educ Res. 1997;14(1):121-130.

25. Gingiss PM, Roberts-Gray C, Boerm M. Bridge-it: a system for predicting implementation success for school-based tobacco prevention programs. Unpublished manuscript.

26. Gingiss PL. A developmental approach to staff development: meeting teachers' post-inservice needs. J Sch Health. 1992;62(5):161-166.

27. Gingiss PL, Gottlieb NH, Brink SG. Increasing teacher receptivity towards use of tobacco prevention education programs. J Drug Educ. 1994;24(2):163-176.

28. Fullan M. Leadership and Sustainability: System Thinkers in Action. Thousand Oaks, Calif: Sage Publications; 2005.

29. Bosworth K, Gingiss P, Potthoff S, Roberts-Gray C. A Bayesian model to predict the success of the implementation of a health education innovation. Eval Program Plann. 1999;22:1-11.

30. Greenberg M. Current and future challenges in school-based prevention: the researcher perspective. Prev Sci. 2004;5(1):5-13. 